\title{
A gestão ambiental de campi universitários sustentáveis
}

Dr. José Aires Trigo

Universidade Estácio de Sá - UNESA Rio de Janeiro/RJ - Brasil

E-mail: jose.trigo09@gmail.com

\section{Dra. Aline Guimarães Monteiro Trigo}

Centro Federal de Educação Tecnológica Celso Suckow da Fonseca -

CEFET/RJ. Rio de Janeiro/RJ - Brasil E-mail: aline.trigo@cefet-rj.br 


\section{Resumo}

A crise ambiental, agravada pelo padrão de consumo desenfreado e por um modelo de produção intensivo em uso de recursos naturais, suscita profundas transformações na forma de pensar e agir, trazendo enlevo ao conceito de Desenvolvimento Sustentável. De forma contundente, o tema passa a fazer parte das agendas de discussões em eventos de magnitude global. O mesmo ocorre no cenário acadêmico, no entanto, esse fato não se aplica apenas à inclusão de disciplinas sobre a temática nos currículos, ou em linhas de pesquisa, mas, para além disso, o repensar das operações diárias dos campi, traduzindose na sua adaptação a parâmetros de sustentabilidade. Nesse sentido, o presente artigo visa discutir a relevância da inclusão da dimensão ambiental nas ações de gestão em campi universitários, buscando uma convergência com as principais recomendações governamentais e não-governamentais. Para tanto se optou pelo uso da pesquisa bibliográfica, de cunho qualitativo e de caráter exploratório.

Palavras-chave: Gestão ambiental. Sustentabilidade. Ensino superior.

\section{Abstract}

The environmental crisis, the pattern of unbridled consumption associated with intensive production model in the use of natural resources provokes deep transformations in the way of thinking and acting, bringing enlightenment to the concept of Sustainable Development. The topic becomes a part of the agendas of discussions at events of global magnitude. The same happens in the academic scenario; however, this fact does not apply only to the inclusion of subjects on the area in the curricula, or researches, but in addition, the rethinking of the daily operations of the campuses and their adaptation to sustainability parameters. In this sense, the present article aims to discuss the relevance of the inclusion of the environmental dimension in management actions on university campuses, seeking a convergence with the main governmental and nongovernmental recommendations. In order to do so, we opted for the use of bibliographic research, qualitative and exploratory.

Keywords: Environmental Management. Sustainability. Higher Education. 


\section{Introdução}

Um número cada vez maior de organizações está convencido de que é um bom negócio a busca pela garantia do futuro de suas empresas incorporando os princípios do desenvolvimento sustentável em todas as suas operações. Hoje, já é fato que não pode haver crescimento econômico em longo prazo, a menos que ele seja sustentável. A partir desse momento, começa a ficar claro que as Instituições de Ensino também devem fazer parte desse discurso em prol da sustentabilidade, desenvolvendo tecnologias e sensibilizando e capacitando o material humano para atender à demanda ambiental e, assumindo uma postura de sustentabilidade em suas operações (TAUCHEN, 2007).

As Instituições de Ensino não devem fugir desse desafio, pois em não usando suas forças combinadas para ajudar a solucionar os problemas emergentes da sociedade global, serão ignoradas no despertar das mudanças. (INTERNATIONAL ASSOCIATION OF UNIVERSITIES, 1993 apud TAUCHEN, 2007, p.55).

O desafio começa no simples reconhecimento da necessidade de se considerar a incorporação dos princípios e critérios da gestão ambiental dentro dos campi universitários no Brasil e no mundo; apesar de estarem dentre os principais ambientes de pesquisa e formação de profissionais da área, observa-se, ao mesmo tempo, a pouca ressonância deste tema entre os administradores escolares, ao menos por enquanto.

Cabe ressaltar que o Governo Federal, por meio da Secretaria de Articulação Institucional e Cidadania Ambiental do Ministério do Meio Ambiente (MMA), tem buscado promover, através da adoção da Agenda Ambiental na Administração Pública (A3P):

\footnotetext{
a sensibilização dos gestores públicos para as questões socioambientais, estimulando-os a incorporar princípios e critérios de gestão ambiental nas atividades rotineiras da administração pública, por meio da promoção de ações que demonstrem o uso racional dos recursos naturais e dos bens públicos, a gestão adequada dos resíduos gerados, a qualidade de vida no ambiente de trabalho, o mínimo de impacto ambiental e máximo de conforto para os usuários nas construções, ações de licitação sustentável/ compras verdes, e ainda o processo de formação continuada dos servidores públicos (MINISTÉRIO DO MEIO AMBIENTE, 2009, p.9).
} 
A Agenda Ambiental na Administração Pública - A3P - é um programa criado pelo Ministério do Meio Ambiente, em 1999, como resposta da administração pública à necessidade de enfrentamento de graves questões ambientais, como: gastar menos energia e água para manter as instalações, gerar o mínimo de resíduos, adquirir produtos que causem menos danos ao meio ambiente e promover condições de trabalho decentes. Ou seja, a organização deve estimular o consumo consciente, o combate ao desperdício e a responsabilidade socioambiental.

Treze anos depois, observa-se a indicação da A3P como um dos programas a serem desenvolvidos para atender à Instrução Normativa n. 10 de 2012, que estabelece regras para elaboração, por parte da administração pública, do Plano de Gestão de Logística Sustentável (PLS). Esse plano permite ao órgão estabelecer práticas de sustentabilidade e racionalização de gastos e processos na Administração Pública (SOLAR, 2013).

Nesse sentido, o objetivo deste artigo é discutir a relevância da inclusão da dimensão ambiental nas ações de gestão em campi universitários, buscando uma convergência com as principais recomendações governamentais e não-governamentais. Metodologicamente, classifica-se, quanto à natureza, como de pesquisa básica, em que o foco é produzir conhecimentos para entender a evolução do tema, e quanto aos objetivos, enquadra-se como pesquisa exploratória, proporcionando maior familiaridade com o tema, e descritiva, que visa descrever as características do fenômeno estudado. Com relação aos procedimentos de pesquisa, optou-se pelo uso da pesquisa bibliográfica (GIL, 2012).

\section{Sustentabilidade}

As dimensões econômica, social, cultural e ambiental se arranjam de forma sistemática no conceito de sustentabilidade, apontando para uma configuração que permite à sociedade expressar seu maior potencial no presente, preservando, ao mesmo tempo, as condições de biodiversidade e os ecossistemas, indefinidamente, para a sociedade. Essa visão sistêmica acrescenta a necessidade de evitar que as atividades humanas interfiram nos ciclos naturais do planeta, preservando o capital natural que será herdado pelas gerações futuras. Assim, a sustentabilidade visa alcançar e manter a 
qualidade de vida, tanto nos momentos de disponibilidade quanto nos de escassez de recursos, por meio de ações fundamentadas na cooperação e solidariedade entre povos e gerações futuras (PORTAL DA SUSTENTABILIDADE, 2017).

Sachs (2009) coloca a dimensão social à frente da ambiental em termos de importância na tentativa de evidenciar as faces da sustentabilidade, muitas vezes percebida "apenas" como ambiental. Segundo ele, a sustentabilidade social destaca-se como a própria finalidade do desenvolvimento, visão corroborada pela constatação de que um colapso social antecederia a uma catástrofe ambiental. Em seguida, viria a dimensão cultural. Já a ambiental seria uma decorrência das anteriores, e a econômica, necessária, mas nunca condição prévia das demais. A essas, seguiriam a sustentabilidade política, fundamental para a reconciliação do desenvolvimento com a conservação da biodiversidade, e a sustentabilidade do sistema internacional para manutenção da paz uma vez que as guerras modernas, além de genocidas, são ecocidas - e do patrimônio comum da humanidade.

\section{A Instituição de Ensino Superior sustentável: a construção de um conceito}

Antes de apresentar este conceito, cabe fazer um breve histórico sobre os importantes eventos e declarações para a implementação da sustentabilidade no ensino superior.

As Instituições de Ensino (IE) têm um papel fundamental na disseminação do desenvolvimento sustentável, principalmente na incorporação de valores e práticas ambientais, tanto nas disciplinas ministradas quanto na administração de suas estruturas físicas (FERES; ANTUNES, 2007).

Cada vez mais, as universidades são convocadas a desempenhar um papel preponderante na Educação voltada para a sustentabilidade:

- Possuem alta concentração de massa crítica, criatividade e potencial tecnológico que podem ser canalizados para as inovações ambientais. O principal ativo presente na Universidade é o conhecimento, e sua organização está centrada na produção, transmissão e difusão dele. 
- Formam os futuros profissionais, lideranças de opinião e potenciais dirigentes de instituições sociais.

- Podem oferecer um testemunho prático do que se prega no ensino, pesquisa e extensão universitária. A Universidade deve praticar o que ensina, para dar o exemplo inclusive sobre os desafios da mudança ambiental.

- Os alunos consideram que estudar em uma universidade cujo campus possui responsabilidade ambiental e compromisso com a sustentabilidade é um diferencial positivo na sua formação (LAYRARGUES, 2011, p.3).

A primeira declaração que fez referência à sustentabilidade no ensino superior foi a Declaração de Estocolmo (1972). Nesse documento ficou estabelecida a necessidade da implementação da educação ambiental já na escola primária, indo até a idade adulta, de forma a incorporar nas pessoas, empresas e comunidade o sentido de responsabilidade relativa à proteção e melhoria do ambiente (ORGANISATION DES NATIONS UNIES POUR L'EDUCATION, LA SCIENCE ET LA CULTURE, 1973 apud MADEIRA, 2008).

Como reflexo dessa conferência, a UNESCO realizou, em 1977, na Geórgia, a Conferência de Tbilisi, que se tornou um marco conceitual ao definir as finalidades, objetivos, princípios básicos e estratégias de desenvolvimento da educação ambiental (CONFERENCIA INTERGOVERNAMENTAL SOBRE EDUCAÇÃO AMBIENTAL, 1977).

Na Bélgica, em 1979, a Associação Universitária para o Meio Ambiente surgiu para juntar as universidades interessadas pelos problemas ambientais e para promover um intercâmbio de informações, constituindo-se num grupo de reflexão e, em 1988, a Conferência de Reitores da Europa envolveu universidades da Europa na cooperação para sustentabilidade (LAYRARGUES, 2011).

Mais tarde, em 1990, teve lugar em Talloires, na França, uma Conferência Internacional que reuniu 22 líderes universitários preocupados com a degradação ambiental. Esses líderes tinham como objetivo avaliar o papel das universidades na criação de um futuro sustentável (CALDER \& CLUGSTON, 2003 apud MADEIRA, 2008).

Da referida conferência, surgiu a Declaração de Talloires, que consiste no estabelecimento de um compromisso, assumido pelos líderes das universidades para se alcançar a sustentabilidade ambiental no ensino superior. $\mathrm{O}$ desafio às universidades foi 
promover a sustentabilidade não apenas através do ensino, mas também na pesquisa e investigação das suas operações e serviços prestados à comunidade (MADEIRA, 2008).

A Declaração de Talloires foi assumida por quase 200 universidades de mais de 40 países (em janeiro de 2011), dentre elas, as brasileiras, Pontifícia Universidade Católica do Rio de Janeiro (PUC-RJ), a Universidade Federal do Rio Grande do Sul (FURG) e a Universidade Federal de São Paulo (UNIFESP). A sua assinatura representou uma série de benefícios em nível institucional, como por exemplo:

1. A instituição passa a fazer parte da rede internacional de universidades e faculdades empenhadas em construir um futuro sustentável;

2. Proporciona motivação a toda a comunidade do campus relativamente a iniciativas ambientais e de sustentabilidade;

3. Constitui um compromisso através do qual a instituição pode ser avaliada ao longo do tempo (TALLOIRES NETWORK, 2017).

Em 1991, a Declaração de Halifax foi subscrita por representantes da Associação das Universidades do Canadá, da Associação Internacional das Universidades (AIU) e da Universidade das Nações Unidas, o que compreende cerca de 33 universidades provenientes de dez países (LAYRARGUES, 2011).

Em 1992, a Conferência das Nações Unidas sobre Ambiente e Desenvolvimento (ECO-92), ocorrida no Rio de Janeiro, teve como resultado a Agenda 21. No seu capítulo intitulado "Educação, Formação e Consciência Pública", o documento refere-se às prioridades atuais do ensino superior quanto a temática de sustentabilidade, como sendo: o desenvolvimento de currículos transdisciplinares, a investigação científica referente à sustentabilidade e à formação de uma rede de organizações e pessoas envolvidas que promova a consciência ambiental (DEPARTAMENTO DAS NAÇÕES UNIDAS DOS ASSUNTOS ECONÔMICOS E SOCIAIS, DIVISÃO PARA O DESENVOLVIMENTO SUSTENTÁVEL, 2007 apud MADEIRA, 2008).

O 15 Congresso da Associação das Universidades do Commonwealth, em 1993, lançou a Declaração de Swansea, que tem como objetivos: 
1. Incitar as universidades a procurar estabelecer e disseminar uma compreensão mais desobstruída do desenvolvimento sustentável desenvolvimento que se encontra com as necessidades do presente sem comprometer as necessidades das gerações futuras e incentivar os princípios e as práticas sustentáveis mais apropriadas do desenvolvimento nos níveis locais, nacionais e globais, consistentes com suas missões.

2. Enfatizar a obrigação ética da geração atual para superar aquelas práticas da utilização do recurso e aquelas circunstâncias difundidas.

3. Destacar a capacidade da universidade de ensinar e praticar princípios sustentáveis, para aumentar o interesse ambiental e para aumentar a compreensão da ética ambiental entre a faculdade, os estudantes e o público em geral.

4. Cooperar com todos os segmentos da sociedade no desenvolvimento de medidas práticas para conseguir a revisão e a reversão eficazes daquelas práticas correntes que contribuem à degradação ambiental.

5. Incentivar universidades a rever suas próprias operações para refletir as melhores práticas sustentáveis (LAYRARGUES, 2011, p.15).

Em fevereiro de 1994 realizou-se a $1^{\text {a }}$ Cúpula Campus Earth, em que participaram cerca de 120 universidades americanas e 29 universidades de outros países. O resultado da Cúpula foi o documento Campus Blueprint for a Sustainable Future, que faz uma série de sugestões às instituições do ensino superior no sentido de trabalharem em busca de um futuro ambientalmente sustentável (Campus Earth Summit, 2007 apud MADEIRA, 2008).

As atas da conferência Campus Earth Summit apontaram as principais características de uma universidade sustentável:

1. A principal prioridade é a sustentabilidade ambiental;

2. O conhecimento ambiental se encontra integrado nas suas disciplinas mais relevantes;

3. Organiza oportunidades para os alunos estudarem os problemas ambientais do campus e também locais;

4. Efetuada auditorias ambientais no campus;

5. Estabelece práticas de compra ambientalmente responsáveis;

6. Procura ativamente reduzir os resíduos produzidos no campus;

7. Apoia alunos que procurem carreiras ambientalmente responsáveis (MADEIRA, 2008, p. 57). 
A Carta Universitária para o Desenvolvimento Sustentável do Programa Copernicus, em setembro de 1994, foi firmada em Genebra, por 196 universidades. Destacam-se os seguintes princípios:

\author{
1. Compromisso Institucional \\ 2. Ética Ambiental \\ 3. Educação dos funcionários universitários \\ 4. Programas de Educação Ambiental \\ 5. Interdisciplinaridade \\ 6. Disseminação do Conhecimento \\ 7. Redes de Trabalho \\ 8. Parcerias \\ 9. Programas de Educação Continuada \\ 10. Transferência Tecnológica (LAYRARGUES, 2011, p. 16).
}

A Rede Internacional de Estudantes para o Meio Ambiente e Desenvolvimento Sustentável (RIEMADES) foi elaborada em 1995, no $1^{\circ}$ Congresso Internacional de Universidades para o Desenvolvimento Sustentável, por uma comunidade universitária motivada pelo compromisso de assumir a função de propulsores do movimento em busca da sustentabilidade. Para isso, torna-se necessário:

(...) introduzir programas-piloto de manejo de resíduos nas Universidades e seu entorno, incluindo a redução, reuso, reciclagem e tratamento de resíduos; e trabalhar em conjunto com os governos nacionais e locais para tornar as universidades centros de investigação, discussão, capacitação e difusão de alternativas técnicas sustentáveis. (LAYRARGUES, 2011, p.27)

Durante a conferência realizada pela UNESCO em 1998, em Paris, se elaborou a "Declaração sobre o Ensino Superior para o século XXI: Visão e Ação", que, em seu artigo $1^{\circ}$, já destaca a promoção do desenvolvimento sustentável e a melhoria da sociedade como missão e valor centrais das instituições de ensino superior, devendo ser preservados, fortalecidos e expandidos. Seguido a isso, em 2002, a UNESCO adotou a Década da Educação para o desenvolvimento sustentável, com início em 2005 e término em 2014, reforçando o objetivo de promover e melhorar a integração da educação para o desenvolvimento sustentável nas estratégias educacionais e nos planos de ação em todos os níveis e setores da educação, em todos os países (UNESCO, 2007 apud MADEIRA, 2008). 
Durante a Rio+10, em 2002, onze importantes organizações internacionais de educação e ciência se reuniram em Johanesburgo para assinar a Declaração Ubuntu sobre Educação, Ciência e Tecnologia para o Desenvolvimento Sustentável. Conclamaram educadores, governos e demais interessados a "rever os programas e currículos de escolas e universidades, a fim de melhor enfrentar os desafios e oportunidades do desenvolvimento sustentável" e "desenvolver mecanismos permanentes para oferecer aos professores e para incorporar aos currículos, informação sobre os progressos no conhecimento científico e tecnológico relevantes ao desenvolvimento sustentável” (LAYRARGUES, 2011, p. 57).

Em 2008, ocorreu um movimento regional para organizar um trabalho cooperativo em rede entre as universidades latino-americanas voltado para a sustentabilidade, que ficou conhecido por Encontro Latino Americano de Universidades Sustentáveis (ELAUS). Várias universidades brasileiras participaram desse primeiro movimento.

Ainda em 2008, a III Conferência Nacional de Meio Ambiente incentivou as Universidades a serem exemplos de sustentabilidade, implantando:

política institucional de meio ambiente para o atendimento às pessoas com necessidades especiais; gestão integrada de resíduos sólidos; tratamento de efluentes gerados, principalmente em laboratórios; programas de arborização permanente com plantas nativas e frutíferas; criação de áreas de preservação ambiental nos campi; elaboração e implantação de plano de gerenciamento de resíduos sólidos de serviços de saúde; inserção da dimensão ambiental nos currículos das licenciaturas de forma a possibilitar a consecução dos objetivos da política nacional e das políticas estaduais e municipais de educação ambiental (LAYRARGUES, 2011, p.54).

$\mathrm{Na}$ Itália, em 2011, foi constituída uma aliança internacional entre 17 universidades para alavancar uma nova evidência acadêmica no ensino sobre Desenvolvimento Sustentável (LAYRARGUES, 2011).

Mais recentemente, na Conferência $\mathrm{RIO}+20$, os países signatários "renovaram seus compromissos com o desenvolvimento sustentável (...) prometendo promover um futuro econômico, social e ambientalmente sustentável para o nosso planeta e para as gerações do presente e do futuro.” (ONU, 2012, não paginado). Com o intuito de fomentar a discussão acercada relevância das Instituições de Ensino Superior como 
ambientes naturalmente privilegiados para discussão sobre o tema, a RIO+20 proporcionou o documento "Desenvolvimento sustentável e educação". No referido documento, um total de 260 grandes universidades de todo o mundo firmaram o compromisso de incorporar as premissas do Desenvolvimento Sustentável no ensino, pesquisa e em suas próprias gestões e atividades organizacionais. Tal ação inspirou a criação da "Declaração para Instituições de Ensino Superior", objetivando nortear a iniciativa "Princípios para Educação e Gestão Responsável" (Principles for Responsible Management Education - PRME).

Em síntese, o documento discute a relevância da criação e manutenção de currículos universitários que ensinem e incentivem a incorporação dos preceitos do Desenvolvimento Sustentável, além do fomento às pesquisas científicas que busquem o desenvolvimento, adaptação, difusão e transferência do conhecimento, dando especial destaque às pesquisas pautadas em tecnologias inovadoras. De forma complementar, ainda foram traçadas diretrizes para a incorporação de boas práticas nas operações diárias das atividades desenvolvidas nos campi; a iniciativa "Green our campuses". O cerne do documento sugere:

i) reduzir a pegada ecológica através da energia, água e eficiência dos recursos materiais em nossos edifícios e instalações; ii) a adoção de práticas de compras sustentáveis em nossas cadeias de fornecimento e serviços de catering; iii) fornecendo opções de mobilidade sustentável para os alunos e professores; iv) a adoção de programas eficazes para a minimização de resíduos, reciclagem e reutilização, e v) promovendo estilos de vida mais sustentáveis (Organização das Nações Unidas, 2012, s.p.).

Portanto, considera-se que uma universidade sustentável é aquela que demonstra ao aluno como ele deve entender a degradação ambiental, bem como o estimula a procurar práticas ambientalmente sustentáveis e que, simultaneamente, os sensibiliza para as reais injustiças (MADEIRA, 2008).

Uma definição também interessante encontra-se no relatório de indicadores de sustentabilidade da Pennsylvania State University (Penn State Green Destiny Council, 2000), apontando que uma faculdade ou universidade sustentável deve apresentar uma perspectiva de longevidade, valores essenciais que incluam o respeito pelos processos 
naturais, preocupação de viver dentro dos limites planetários, prestação de contas dos custos totais e a responsabilidade cívica.

\section{Casos de sustentabilidade em Instituições de Ensino Superior}

Assim, dada a importância que o ensino superior deve ter no desenvolvimento e implementação da sustentabilidade, são apresentados os principais esforços realizados na sua caminhada em direção a um futuro sustentável.

A aplicação da gestão ambiental em uma instituição de ensino tem como função minimizar e controlar, bem como evitar os problemas ambientais internos e externos à instituição. Tauchen e Brandli (2006) completam que os benefícios de um SGA são diversos e, entre eles, destacam-se:

\footnotetext{
a) as economias pelo aumento da produtividade e pela redução no consumo de energia, água e materiais de expediente; b) o estabelecimento das conformidades a partir do atendimento a legislação ambiental, reduzindo, assim, os riscos de a instituição incorrer em penalidades ou gerar passivos ambientais; c) a evidência de práticas responsáveis e a melhora na imagem externa da instituição; e d) a geração de oportunidades de pesquisa. (TAUCHEN; BRANDLI, 2006, p. 504).
}

No entanto, verifica-se que a sua sistemática ainda é pouco estruturada, sobretudo nas Instituições de Ensino fundamental e médio no Brasil. Além disso, existe uma diferenciação qualitativa clara entre as práticas implementadas por Instituições de Ensino fundamental, médio e superior (FERES \& ANTUNES, 2007).

As iniciativas em gestão ambiental observadas em Instituições de Ensino fundamental e médio, que representam a maior parcela das Instituições de Ensino no Brasil, estão muito associadas a práticas de educação ambiental específicas e, em alguns casos, à implantação de programas de racionalização do consumo de água e energia elétrica, geralmente focados na redução de custos e na sensibilização dos alunos (FERES \& ANTUNES, 2007). 
De acordo com Tauchen e Brandli (2006), apesar de representarem apenas 0,5\% do número total de Instituições de Ensino no Brasil, as IES possuem um grande potencial para geração de aspectos ambientais ${ }^{1}$ significativos. Isso vem ao encontro do que Tauchen e Brandli (2006) estabelecem como agentes significativos para implantação de um SGA nesses tipos de instituição.

Entre elas está o fato de que as faculdades e universidades podem ser comparadas com pequenos núcleos urbanos, envolvendo diversas atividades de ensino, pesquisa, extensão e atividades referentes à sua operação, como bares, restaurantes, alojamentos, centros de conveniência, entre outros serviços. Além disso, um campus precisa de infraestrutura básica, como redes de abastecimento de água e energia, redes de esgoto e drenagem pluvial e vias de acesso (TAUCHEN \& BRANDLI, 2006, s.p.).

Por estarem envolvidas diretamente com a pesquisa e o desenvolvimento de processos e tecnologias, as universidades em geral apresentam programas de gestão ambiental mais estruturados. Entretanto, mesmo nessas instituições, a adoção de práticas de gestão sistêmicas e abrangentes voltadas à questão ambiental ainda é recente (FERES \& ANTUNES, 2007).

As ações sustentáveis que mais aparecem em um SGA em uma instituição de ensino são o controle do consumo de água (e sua reutilização) e o programa de coleta seletiva de resíduos, seguidos do treinamento e sensibilização dos alunos. Outros dois aspectos que aparecem são a auditoria ambiental (para evidenciar não-conformidades) e o diagnóstico dos impactos diretos ou significativos para o ambiente (TAUCHEN \& BRANDLI, 2006).

Ribeiro e colaboradores (2005 apud. TAUCHEN \& BRANDLI, 2006) apontam que a existência de barreiras a uma possível implementação de políticas ambientais é muito comum, dentre as quais podem ser destacadas: a) a ausência de informação da sociedade sobre práticas sustentáveis; b) a não valorização do meio ambiente por diversos colaboradores da organização; e c) a não percepção da universidade como uma fonte potencial de poluição.

\footnotetext{
${ }^{1}$ Aspectos ambientais são aqui entendidos como as saídas do sistema que possuem uma interface com o meio ambiente. Em outras palavras, é a ação produzida pelo homem através de equipamentos ou plantas operacionais que geram ou podem gerar uma reação do meio ambiente (BARBIERI, 2011).
} 
Em muitos estudos fica claro que, para o bom funcionamento da política ambiental, a participação de todos os indivíduos é primordial, e principalmente da Alta Administração da IE. É ela que garantirá as profundas transformações a serem empreendidas. Mas essa participação não se verifica de forma totalmente espontânea; ela precisa ser estimulada. Assim, para que um SGA possa se tornar efetivo e ser incorporado por todos os indivíduos envolvidos é necessário que um programa de educação ambiental acompanhe todo o processo de implantação e execução do sistema, visando, inclusive, à sua continuidade. É o programa de educação ambiental que fomentará a elaboração de comportamentos positivos com respeito ao meio ambiente e à sua utilização racional (BUTZKE et al., 2002).

Para Barbieri (2011), a educação ambiental deve estimular as pessoas a serem portadoras de soluções e não apenas de denúncias, embora estas devam ser as primeiras atitudes diante dos desmandos socioambientais. Deve também produzir mudanças nas suas próprias condutas modificando, por exemplo, seus hábitos de consumo.

As universidades passaram a inserir a temática ambiental em seus esquemas de gestão a partir dos anos sessenta. As experiências iniciais surgiram nos Estados Unidos, concomitantemente com as promoções de profissionais nas ciências ambientais, que se estenderam ao longo dos anos setenta. Já nos anos oitenta, o que se evidenciou foram as políticas mais específicas à gestão de resíduos e à eficiência energética. Durante a década de noventa, desenvolveram-se políticas ambientais de âmbito global, que reúnem todos os tipos de organizações (TAUCHEN \& BRANDLI, 2006).

Dias (2006, p. 50) aponta, em seu estudo realizado na Universidade Católica de Brasília, que o marco referencial adotado no projeto de educação ambiental fundamenta-se nas orientações da Política Nacional de Educação Ambiental (Lei no 9.795/99). E diz ainda:

(...) essa política baseia-se nas recomendações das Grandes Conferências Intergovernamentais sobre Educação Ambiental, promovidas pela Unesco - PNUMA, por meio do seu Programa Internacional de Educação Ambiental (Tbilisi, 1977; Moscou, 1987) corroboradas na Conferência da ONU sobre o Meio Ambiente e Desenvolvimento (Rio - 92), Conferência sobre a Sustentabilidade Humana (Rio+10, Johannesburgo, África do Sul, 2002) e do Programa de Educação Ambiental dos Ministérios do Meio Ambiente e da Educação, bem como da Diretoria de Educação Ambiental do 
Ibama (Educação no processo de Gestão Ambiental) (BRASIL, 1999, s.p.).

Nesse sentido, a Proposta de Diretrizes Curriculares Nacionais para Educação Ambiental, encaminhada ao Conselho Nacional de Educação - CNE, enfatiza, no seu item III, a sustentabilidade e aponta seis pontos fundamentais, a saber:

- Promoção do enfoque da sustentabilidade em seus múltiplos aspectos, por meio de atividade curricular/disciplina/projetos interdisciplinares obrigatórios que promovam o estudo da legislação ambiental e conhecimentos sobre gestão ambiental, de acordo com os cursos de bacharelado, tecnologia, especialização e extensão das instituições públicas e privadas de nível superior voltadas para a formação de profissionais que atuam nas diferentes áreas.

- Fomento a pesquisas voltadas à construção de instrumentos, metodologias e processos para a abordagem da dimensão ambiental que possam ser aplicados aos currículos integrados dos diferentes níveis e modalidades de ensino.

- Acompanhamento avaliativo da incorporação da dimensão ambiental na educação superior de modo a subsidiar o aprimoramento dos projetos pedagógicos e a elaboração de diretrizes específicas para cada um de seus âmbitos.

- Fomento e estímulo à pesquisa e extensão nas temáticas relacionadas à educação ambiental.

- Incentivo à promoção de materiais educacionais que sirvam de referência para a educação ambiental nos diversos níveis de ensino e modalidades de ensino e aprendizagem.

- Participação em processos de formação continuada e em serviço de docentes (MINISTÉRIO DA EDUCAÇÃO, 2017, p. 22).

Logo, não há como negar o papel da universidade, destacando-se, além do caráter formativo para a emancipação e exercício da cidadania, o de "atuar como agente promotor e articulador de debates que contemplem os diversos aspectos da vida social e conduzam a propostas capazes de melhorar as condições de vida da comunidade" (IPES, 2001 apud SOUSA et al., 2011, p. 5).

A despeito de tudo o que foi dito, os casos de gestão ambiental encontrados nas universidades do Brasil e do mundo são, na maioria das vezes, práticas isoladas em circunstâncias em que a instituição já está em funcionamento. 
Em novembro de 2009, a PUC-Rio lançou sua Agenda Ambiental, criada pelo Núcleo Interdisciplinar de Meio Ambiente com a participação de 40 professores de todos os departamentos da universidade. As metas foram divididas em sete tópicos (Biodiversidade, Água, Energia, Atmosfera, Materiais, Resíduos e Educação Ambiental) a se concretizar em até dez anos (LAYRARGUES, 2011).

A Universidade Federal de Viçosa, em meados de 2009, por meio da Comissão de Resíduos e Rejeitos Tóxicos, Químicos, Biológicos e Radioativos, disponibilizou o serviço de coleta de resíduos perigosos. Foram instalados coletores especiais em vários prédios, onde podem ser depositadas lâmpadas, baterias e pilhas. Os resíduos laboratoriais e lâmpadas fluorescentes foram encaminhados à Comissão, mediante agendamento. $\mathrm{O}$ material coletado será armazenado em um depósito na universidade e depois recolhido por uma empresa especializada, para a destinação adequada (LAYRARGUES, 2011).

Em setembro de 2010, os servidores da Universidade do Estado do Pará (UEPA) participaram de uma ação para promoção de uma cultura de responsabilidade socioambiental e valorização do meio ambiente (LAYRARGUES, 2011).

Um dos exemplos brasileiros importantes de universidade que implementou um SGA é o da Universidade do Vale do Rio dos Sinos (UNISINOS) com a adoção do projeto "Verde Campus", além de ter sido a primeira universidade da América Latina a ser certificada segundo a ISO 14.001 (TAUCHEN \& BRANDLI, 2006).

Outro importante exemplo já citado foi o Programa de Educação Ambiental desenvolvido pela Universidade Católica de Brasília (PEA-UCB), cujo objetivo geral é incorporar a dimensão socioambiental nas ações da UCB, em prol da sustentabilidade humana. Além disso, o PEA-UCB tem sido benchmarking ${ }^{2}$ de diversas empresas brasileiras. Uma delas é a Centrel S.A., empresa de proteção ambiental do Polo Petroquímico de Camaçarí-BA, portadora das certificações ISO 9.000, ISO 14.001, OSHAS 18.000 e outras (DIAS, 2006).

A Universidade de São Paulo, por exemplo, desenvolveu três programas voltados à gestão ambiental em seus campi universitários: o Programa de Uso Racional de Água

\footnotetext{
${ }^{2}$ Benchmarking é um processo sistemático e contínuo de avaliação dos produtos, serviços e processos de trabalho das organizações que são reconhecidas como representantes das melhores práticas, com a finalidade de comparar desempenhos e identificar oportunidades de melhoria na organização que está realizando (ou monitorando) o benchmarking (DIAS, 2006).
} 
(PURA-USP), o Programa de Uso Eficiente de Energia (PURE-USP) e o USP Recicla, voltado à gestão de resíduos sólidos. Já a área de saúde da Universidade Estadual de Campinas (UNICAMP) possui um Programa Gestor de Resíduos Radioativos, Biológicos e Químicos. Além da presença de uma Comissão de Ética Ambiental com o objetivo de analisar e emitir pareceres para a destinação final dos resíduos oriundos dos projetos de pesquisas desenvolvidos na Universidade, principalmente alternativas técnicas voltadas à substituição de equipamentos sanitários (FERES \& ANTUNES, 2007).

A Universidade da Organização das Nações Unidas, em Tóquio, no Japão, adotou compromissos e políticas ambientais para o desenvolvimento sustentável, e certificou-se pela norma ISO 14.001 (LAYRARGUES, 2011).

Ribeiro et al. (2005 apud TAUCHEN \& BRANDLI, 2006) citam que a Universidade Mälardalen, na Suécia, também implantou um SGA e certificou-se pela norma ISO 14.001. Ainda nessa perspectiva, iniciou-se na Europa o projeto "Ecocampus", que é um sistema de gerenciamento ambiental direcionado às universidades.

Em Portugal, em 1998, o projeto "Campus Verde" implementou um Sistema de Gestão Ambiental na Faculdade de Ciências e Tecnologia/ Universidade Nova de Lisboa (FCT/UNL), a primeira Instituição de Ensino Superior portuguesa com um certificado de gestão ambiental. Tudo começou com a realização do primeiro levantamento ambiental do campus, iniciado por um grupo de alunos da Licenciatura em Engenharia do Ambiente no âmbito da disciplina "Auditoria e Ecogestão" (LAYRARGUES, 2011).

A Universidade de Waterloo, no Canadá, foi considerada um caso de boas práticas de sustentabilidade no ensino superior. Essa universidade criou uma política ambiental bastante forte através da constituição de uma comissão em 1990, a Watgreen Committee, cujos objetivos eram promover atividades ambientais no campus e atuar como um órgão de natureza consultiva para o governo (UNIVERSIDADE DE WATERLOO, 2007 apud MADEIRA, 2008).

De acordo com Weenen (2000 apud MADEIRA, 2008), algumas das principais medidas adotadas na Universidade de Waterloo que obtiveram sucesso foram: a promoção em todo o campus de políticas de utilização de energias alternativas e de redução do consumo de energia; o estabelecimento de acordos comerciais com empresas 
ambientalmente responsáveis, através do que convencionaram chamar de "ecocompras"; e todas as partes isoladas do campus foram substituídas por paisagem natural e plantas nativas.

\section{Considerações Finais}

A despeito do extenso debate acerca da adequação às premissas do Desenvolvimento Sustentável em campi universitários, efetivamente, os resultados ainda estão longe do ideal. Os avanços se fazem necessários, pois, a lógica de sua relevância reside no fato de que as Instituições de Ensino Superior, por essência, são espaços férteis para o surgimento de ideias, seguido pela experimentação e discussão. Nesse ciclo virtuoso, o principal desafio tem sido a incorporação de atitudes que tenham convergência com as premissas de "boas práticas" ambientais, no dia a dia operacional dos campi universitários. O vulto de tal argumento se associa ao fato de que é nesses espaços que se formam a maioria das pessoas que organizam e dirigem instituições na sociedade.

Dado o fato, mostra-se flagrante a carência de atitudes concretas e eficientes, além de sua divulgação, visando ao resgate de valores e à criação de novos, sintonizados com uma nova ética global.

Nesse sentido, ganham impulso os diversos instrumentos de gestão ambiental como o processo de educação ambiental, que tem papel preponderante na viabilização dessas atitudes, na medida em que dela depende a conscientização de que o homem é parte integrante do meio ambiente; os licenciamentos ambientais; as certificações e o aperfeiçoamento das leis ambientais e dos mecanismos de participação popular- que vêm propiciar uma conjunção harmoniosa entre a preservação ambiental, a responsabilidade social e o desenvolvimento econômico, o que é conhecido como Desenvolvimento Sustentável.

Levando em conta a profusão de iniciativas ambientais nas últimas décadas e os documentos que decorrem de suas discussões, salienta-se a aquiescência de que as Instituições de Ensino Superior exercem um papel fulcral na incansável busca por uma sociedade mais justa e promotora da sustentabilidade ambiental, por meio da articulação 
de discussões sobre um modelo de desenvolvimento menos intensivo no uso dos recursos naturais e pautado em um consumo mais consciente.

Dias (2006) revela que as instituições acadêmicas, catalisadoras do metabolismo intelectual, ainda reagem de forma tímida; no entanto, suas práticas revelam uma visão autocentrada, fragmentada e desconectada dos reais desafios socioambientais da sociedade. Portanto, para que se naturalize a relevância da questão ambiental na percepção dos indivíduos, mais importante do que oferecer uma formação acadêmica sobre o tema, faz-se necessária a promoção de um ambiente em que se vivencie essa experiência em todos os níveis da comunidade universitária.

Os parâmetros que distinguem uma Instituição de Ensino Superior como sustentável são contribuições relevantes no caminho de buscar a excelência; contudo, esses parâmetros são muito gerais e carecem de informações para sua implantação e melhor integração dentro das rotinas administrativas e operacionais das instituições de ensino superior.

Nesse sentido, entendendo que esta discussão não se esgota facilmente, buscamos contribuir com reflexões que, em síntese, apontam para a necessidade de compreender que os resultados precisam ser percebidos, não apenas nos efeitos econômicos diretamente relacionados aos campi, mas de forma mais profunda e, de longo prazo, naturalizar o comprometimento da comunidade universitária quanto aos resultados de suas ações ambientais presentes e seus impactos para o futuro do planeta e das próximas gerações.

\section{Referências}

BARBIERI, J. C. Gestão Ambiental Empresarial: conceitos, modelos e instrumentos. 3 ed. Rio de Janeiro: editora Saraiva, 2011.

BRASIL. Política Nacional de Educação Ambiental. Lei no 9795 de 27 de abril de 1999. Disponível em: <http://www.planalto.gov.br/ccivil 03/Leis/L9795.htm> Acesso em: 27 mar. 2017. 
BUTZKE, I.C.; PEREIRA, G.R.; NOEBAUER, D. Sugestão de indicadores para avaliação do desempenho das atividades educativas do sistema de gestão ambiental SGA da Universidade Regional de Blumenau - FURB, v. 13, 2002. Revista eletrônica do mestrado em educação ambiental. Disponível em $<$ http://www.fisica.furg.br/mea/remea/congress/artigos/comunicacao13.pdf $>$ Acesso em 20 mar. 2017.

\section{CONFERÊNCIA INTERGOVERNAMENTAL SOBRE EDUCAÇÃO} AMBIENTAL. Algumas recomendações da conferência intergovernamental aos países membros. Tbilisi, CEI, de 14 a 26 de outubro de 1977. Disponível em: < http://www.fzb.rs.gov.br/upload/20130508155354tbilisi.pdf > Acesso em: 5 mar. 2017.

DIAS, G. F. Educação e Gestão Ambiental. São Paulo: Gaia, 2006.

FERES, Y. N.; ANTUNES, F. Z. Gestão ambiental em instituições de ensino: programa eco eficiência e sistema de gestão ambiental do SENAC São Paulo. IX ENGEMA, Encontro Nacional sobre Gestão Empresarial e Meio Ambiente. Curitiba, 2007. Disponível em <http://www.engema.up.edu.br/arquivos/engema/pdf/PAP0337.pdf> Acesso em: 20 mar. 2017.

GIL, A.C. Métodos e técnicas de pesquisa social. 6. ed. São Paulo: Atlas, 2012.

LAYRARGUES, P. P. Gestão Ambiental e Universidades: um caminho pedagógico para a sustentabilidade. Brasília: Cidade Gráfica e Editora, 2011. Disponível em: < http://www.foruns.unicamp.br/foruns/projetocotuca/biblioteca virtual/arquivos/Phillpi. pdf > Acesso em: 15 mar. 2017.

MADEIRA, A. C. F. D. Indicadores de sustentabilidade para instituições de ensino superior. 2008. 220 f. Dissertação (Mestrado em Engenharia do Ambiente) - Faculdade de Engenharia da Universidade do Porto. Porto, 2008.

MINISTÉRIO DA EDUCAÇÃO - MEC. Proposta de Diretrizes Curriculares Nacionais para a Educação Ambiental. Disponível em:<

http://portal.mec.gov.br/dmdocuments/publicacao13.pdf > Acesso em: 29 mar. 2017.

MINISTÉRIO DO MEIO AMBIENTE - MMA. Secretaria de Articulação Institucional e Cidadania Ambiental. A3P. Agenda Ambiental na Administração Pública. 5 
Edição. Brasília. 2009. Disponível em: < http://www.mma.gov.br/responsabilidadesocioambiental/a3p/> Acesso em 25 mar. 2017.

ONU - ORGANIZAÇÃO DAS NAÇÕES UNIDAS. Os resultados da RIO+20. Não paginado, 2012. Disponível em: $\langle$ http://www.onu.org.br/rio20/tema/desenvolvimentosustentavel/> Acesso em: 18 mar. 2017.

PENN STATE GREEN DESTINY COUNCIL. Penn State Indicators Report 2000: Steps Toward a Sustainable University, 2000. Disponível em:

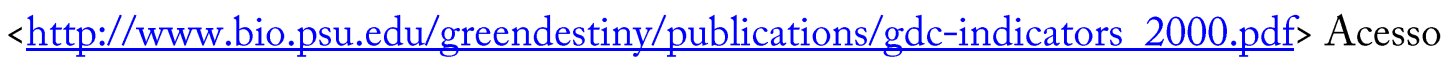
em 28 mar. 2017.

PORTAL DA SUSTENTABILIDADE. Página Inicial e Seção Conceitos. Disponível em: <http://portaldasustentabilidade.ufrgs.faccat.br/moodle/> Acesso em: 23 mar. 2017.

SACHS, Ignacy. Caminhos para o desenvolvimento sustentável. Rio de Janeiro: Garamond, 2009.

SOLAR. Curso de Capacitą̧ão Sustentabilidade na Administração Pública. Agenda Ambiental na Administração Pública. A3P. Brasília-DF. Agosto de 2013.

SOUSA, M. G. B.; CARNIELLO, M. F.; ARAUJO, E. A. S. O Papel das Instituições de Ensino Superior no Desenvolvimento Sustentável. In: Encontro de PósGraduação as contribuições da ciência para a sustentabilidade do planeta, 2011, São José dos Campos, SP. XII Encontro Latino Americano de Pós-Graduação. São José dos Campos, SP: UNIVAP, 2011.

TALLOIRES NETWORK, Who we are. 2017. Disponível em: $<$ http://talloiresnetwork.tufts.edu/> Acesso em: 14 mar. 2017.

TAUCHEN, J. A. Um modelo de gestão ambiental para implantação em instituiçães de ensino superior. 2007. 149f. Dissertação (Mestrado em Engenharia do Ambiente) Faculdade de Engenharia e Arquitetura da Universidade de Passo Fundo, Passo Fundo, 2007. Disponível em: < http://www.ppgeng.upf.br/images/stories/2005joeltauchen.pdf >. Acesso em: 12 mar. 2017. 
TAUCHEN, J.; BRANDLI, L. L. A gestão ambiental em instituições de ensino superior: modelo para implantação em campus universitário. Gestão EPProdução, São Carlos, v. 13, n. 3, p. 503-515, Dec. 2006. Disponível em:<http://www.scielo.br/scielo.php?script=sci arttext\&pid=S0104530X200600030001 2\&\&lng=en\&nrm=iso 